Original Research Paper

\title{
Double Working Day in Female Higher Education Teachers in Mexico City
}

\author{
María del Carmen López García \\ Escuela Nacional de Medicina y Homeopatía, \\ Instituto Politécnico Nacional, Ciudad de México, México
}

\author{
Article history \\ Received: 11-07-2017 \\ Revised: 23-09-2017 \\ Accepted: 13-11-2017
}

Tel: 525551191620

Email: mc.lpzg@gmail.com

\begin{abstract}
Nowadays, women are fully integrated to all the productive sectors of life. However, women continue to be the only responsible ones for housework and reproductive work. This paper analyzes the perception of women University professors with a double workday in Mexico City. We use the Participatory Action Research methodology. The diagnosis results show that these women perceive their conflict situation as natural, but changing.
\end{abstract}

Keywords: Participatory Action Research, Female Teachers, Double Working Day

\section{Introduction}

In the 19th century, during the industrialization process, work and family spaces were separated, as well as tasks, based on gender; women were assigned the obligation to take care of children, as well as housework, and men were assigned the family economic provisioning. These two spaces were also given a hierarchical order, and the masculine was transformed into the superior, and the feminine, into the inferior and subordinate (Wainerman, 2007). As a result, qualities as devotion, self-denial, obedience and sacrifice were attributed to women and, along with other qualities, formed the stereotype of the "good wife and good mother", which has been in place for many years.

In the last few decades, aspects such as gender struggle, higher demands of the labor market and Free Trade Agreements have favored the integration of women into the workplace. This, in addition to being responsible for the house and family, and the persistence of the before mentioned stereotype, even if somewhat relaxed and evolved. Lan (2001) referred to the work carried out in the family or household space as "reproductive". And to the work that takes place outside, either in offices, factories, universities or hospitals, among others, as "productive". In this study they will be referred to in the same way; the performance of both types of work simultaneously will be referred to as "double working day".

In other aspects, since 1981, the International Labour Organization (ILO) refers to the new challenges posed by phenomena such as the expansion of women's paid work, and the need to reconcile work and family life, and requests on its Convention 156 On equal opportunities and equal treatment for men and women workers: workers with family responsibilities, that all member countries include among the objectives of their National Policy that persons with family responsibilities who are engaged or wish to engage in an employment, can do so without being subject to discrimination and, to the extent possible, without conflict between their employment and family responsibilities (ILO, 1981).

However, in women workers, this conflict goes beyond the legal and the simple distribution of a schedule. It involves the breakdown of cultural patterns, stereotypes, whose effects can be reflected both at the individual and organizational levels.

At the individual level, from the cognitive psychology perspective, Cerros-Rodríguez and RamosTovar (2009) considered that the factors that may generate conflict and emotional effects in these women depend on the life cycle of each one of them, as well as on their structure and family dynamics. This means that women with a moral imperative product of a culture that tells them how to be a "good wife and good mother", can have emotions of anger or guilt, when feeling that they do not comply with what "should be".

At the organizational level, there are studies like the one performed by Rico (2012), which state that the greater job satisfaction is obtained when the person has managed to reconcile family life with work. And that this satisfaction, at the end, has an impact on the best performance, health, and longevity of workers (Spector, 2002). In addition, Fernández (2005), and Argüelles et al. (2013) claim that job satisfaction is an advocate of higher

With regard to woman teachers in Mexico, according to data from INEGI (2015), they occupy 62 percent of the positions. However, at the University level this figure is lower: only 44 percent (INEGI, 2015). productivity and quality of working life. 
According to data collection carried out by Ordorika (2015), female participation in higher education decreases significantly in the transition between the master's and doctorate degrees and even more so, at the level of academic researchers. It says that, at the National Autonomous University of Mexico (UNAM), academic women represent 42.2 percent of the plant, but that they only occupy 26.9 percent of higher-level appointments.

That means that, although the number of women, both students and academicians, as well as administrative workers has increased in higher education institutions, the process has not represented, by itself, conditions of equity between women and men, which according to Buquet-Corleto (2011) is the result of factors such as historically accumulated inequality, double working day, or gender stereotypes.

This is paradoxical, since most of the contributions in gender matters have come from Universities. According to Díaz-Barriga et al. (2006), what happens in these educational contexts is that diversity and equity recognition is in conflict with the hegemonic visions on society, profession or knowledge universality.

With regard to the situation of women who perform both types of work, literature documents two positions. One of them, in which family represents a difficulty when combining both responsibilities, and the other, in which family is not only not a difficulty, but it is actually a support in very stressful labor situations.

The first one considers, as stated by Acker (1995) and Fernández-Rius (2000), that both family and professional career are highly demanding, exacting and conflicting areas, since in both of them, excellence is looked for. From this perspective, woman must decide whether to give greater attention to her family, which means lower productivity, efficiency and competitiveness as an academic, or devote greater effort to her professional area, "neglecting" her family.

In the second position: support-family, researchers like Cerros-Rodríguez and Ramírez-Tovar (2011) point out the importance of the contribution of social networks and mainly of the spouse, to the professional performance of University women scientists. And, in this situation, productive work will not be referred to as a source of conflict for women, but, on the contrary, it represents a space where experiences can be shared, and problems can be socialized, as well as the opportunity to gain economic independence, recognition and satisfaction.

This study was conducted in order to analyze the perception of woman teachers from a higher education institution in Mexico City, with regard to their double working day.

\section{Materials and Methods}

The Participatory Action Research (PAR) method, where workers investigated are not only objects of study, but become active subjects of research and seek to transform their reality, was applied. The phases into which PAR is divided are: diagnosis, planning, implementation, evaluation and feedback of the plan and resulting actions, and again, planning (Baum et al., 2006). In this study, only the first part was carried out: the diagnosis or identification of needs, for which the pictureword technique was used as an exploratory survey for the contextualization and location of thematic axes. And later, the group work one, with individual survey and group discussion on the thematic axes found in the first phase.

The sample was composed of six-woman teachers with at least five years in the position. The average age of participants was 48 years; their average duration in their position was 17 years. Sixty-seven percent had a master's degree, and the rest of them, a bachelor's degree. Sixty-seven percent reported having a couple. The average time they stated to devote to their reproductive work was 2 to 6 hours (average 3 hours).

\section{Results}

As a result of the picture-word technique, we found five basic thematic axes which are the elements that make up the double working day of the participating teachers, and they are shown in Fig.1.

With regard to the results of the individual survey and the group discussion carried out around the aforementioned thematic axes, the following was found.

During group work, general comments were positive.

\section{Productive Work}

Productive work generates satisfaction, development opportunities, and economic independence, and, as stated by them: "My work allows me to fulfill myself in what I like" and "With my work, I feel full".

\section{Reproductive Work}

Reproductive work was referred to as satisfactory, even if some participants rated it as "boring" and stated: "I don't like cooking" and "I feel that cooking makes me lose time".

They assured that it is a great responsibility, which demands more help. And they also commented: "We need to involve the whole family in housework. If we don't, it is impossible".

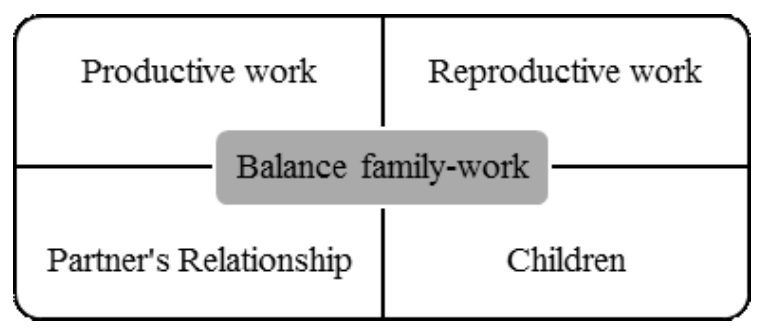

Fig. 1: Thematic axes in teachers' double working day 


\section{Children}

Regarding children, teachers stated that they were "their motivation", but require too much attention and mean a great commitment.

\section{Relationship with their Couple}

About the relationship with their couple, they said: "He helps". That means their couple provides support, but the responsible ones for household activities were them. And they explain that this support didn't exist at the beginning of the relationship; they need to talk in order to increase it progressively.

\section{Family-Work Balance}

They stated that family-work balance was affected by double workday in both sides: family and work. But that it was a "normal" situation, and that it "always", happened to every woman who wanted to work out of home.

One of them said: "I can't take care of my family properly... I have just a few hours to spend with them" or "I try everything to go well, but any inconvenience unbalances all".

And they specifically state that almost always "We must establish in every moment what is more important...family first and then work, and solve problems one at a time, as they occur".

\section{Solution Alternatives}

Finally, the solutions for conflict situations that they have implemented and proposed are: to distribute their time between both types of work. And, as one of the participants said: "We must program what is strictly necessary for both types of work, and respond with priorities; we must start with the urgent and hope that everybody helps with household activities". Also, they said: "We need to start with children education and reinforce it every day".

And they ensure that balance between their work and family life can be achieved, but having family support, organization, planning and time distribution.

\section{Discussion}

In general, woman teachers participating maintained, even when more flexible, the same gender stereotyping that promotes the division of labor based on gender, perhaps because of their average age (48 years). Results show that they perceive their situation as one of conflictfamily, which coincides with what is stated by Acker (1995) and Fernández-Rius (2000). However, they state to be in the transition to a support-family, which is consistent with the results of Cerros-Rodríguez and Ramírez-Tovar (2011). They ensure that support is on the rise by partner and children, and they perceive their conflict situation as something "natural" that should only be accepted and dealt with.
In addition, they show guilty feelings because they say not to take care of their family "properly" and they spend few time with them. That is, they do not comply with what their moral imperative demands them: To be a "good wife and good mother", as explained by CerrosRodríguez and Ramos-Tovar (2009).

Also, the priority that participants always give to family is observed, and an aspect to be noted is their way of solving conflict, on the basis of performing only basically required academic activities, the "urgent", thus slowing down their creativity and productivity, at a disadvantage for their development and promotion, as also stated by Acker (1995).

\section{Conclusion}

With regard to method, Participatory Action Research is considered to be indicated for studies such as the one carried out, since it returns the protagonist role to subjects involved, brings together their perceptions, and coordinates their proposals for change on a common problem. In this research, it is still missing to plan, carry out action proposals, evaluate and give feedback on the plan.

With regard to the diagnosis established with respect to their double working day, it was found that woman teachers participating perceive their conflict situation as normal: something that must be accepted and dealt with. And, even if they feel some degree of guilt for not complying with their cultural patterns of "good wife and good mother", they understand that these patterns are changing, and they are struggling to contribute to such change by raising their children in a different way. This is reflected in the process of change that is slowly taking place in family organization and, in general, in gender cultural patterns in Mexican society.

In relation to balance that can be established by teachers between their work and family, we agree with Buquet-Corleto (2011) in that, although it is a private matter, it is important that educational institutions critically analyze what their members require in order to form more equitable and productive institutions.

Even more so if it is thought that, given their function as nurturers of human resources, the progress achieved in these higher education institutions in which 44 percent of their teaching staff is occupied by women (INEGI, 2015), will have an impact in all the areas that make up our society.

Finally, the change in stereotypes and cultural patterns should be reflected by facilitating what ILO has been requesting since 1981: that those who are engaged or wish to engage in employment are able to do so, to the extent possible, without conflict to reconcile work and family life (ILO, 1981). 


\section{Acknowledgment}

There was not any financial support, neither technical assistance to report.

\section{Conflict of Interest}

There is no conflict of interest.

\section{Author's Contributions}

María del Carmen López-García: Investigation's conception and design, acquisition of data analysis, interpretation of data and reviewing for significant intellectual content.

\section{Ethics}

This article is original and contains unpublished material. The corresponding author confirms that there is no ethical issues involved.

\section{References}

Acker, S., 1995. Gender and Education. Ed Nancea. Madrid, Spain.

Argüelles, L., R. Quijano and J. Sahui, 2013. Job satisfaction as a promoter of the quality of working life in the folksy tourism sector employees in Campeche, México. Revista Iberoamericana para la Investigación y el Desarrollo Educativo, 10: 1-19.

Baum, F., C. MacDougall and D. Smith, 2006. Participatory action research. J. Epidemiology Community Health, 60: 854-857. DOI: $10.1136 /$ jech.2004.028662

Buquet-Corleto, A.G., 2011. Mainstreaming of gender in higher education. Conceptual and practical problems. Perfiles Educativos, 23: 211-225.

Cerros-Rodríguez, E. and M.E. Ramos-Tovar, 2009. Speaking of gender, and emotions in academic women's high performance. Perspectivas Sociales, 11: 187-210.
Cerros-Rodríguez, E. and M.E. Ramos-Tovar, 2011. The role of the partner in the professional development of university women investigators. Rev. Pequén.

Díaz-Barriga, F., G. Hernández, M.A. Rigo, E. Saad and G. Delgado, 2006. Current challenges in the formation and practice of the educational psychologist.

Fernández, E., 2005. Management. Valencia, Spain. ISBN: 9788497057509.

Fernández-Rius, L., 2000. Gender roles- academic women conflicts? University of Havana.

ILO, 1981. Convention 156 Workers with Family Responsibilities. International Labor Organization.

INEGI, 2015. Instituto Nacional de Estadística y Geografía (México).

Lan, D., 2001. Double workday and invisibility of women's work. Notes from a case. Proceedings of the of the 5th National Work Studies Congress of the Labor Studies Argentine Association, Aug. 1-3.

Ordorika, I., 2015. Gender equity in higher education. Revista de la Educación Superior, 14-2: 7-17.

Rico, P., 2012. Job satisfaction of employees in Spain. Revista de Métodos Cuantitativos para la Economía y la Empresa, 14: 137-158.

Spector, P., 2002. Industrial and organizational psychology: research and practice. Ed. El Manual Moderno, México. ISBN-10: 0470949767.

Wainerman, C., 2007. Family, Work and Gender Relationships. In: Levín between family and work, Relations, Conflicts and Gender Politics in Europe and Latin America, Carbonero-Gamundí, M.A. (Ed.). Homo Sapiens, Rosario, Argentina. ISBN: 978-950-808-518-4. 